\title{
Role of Auriculotherapy in the Treatment of Temporomandibular Disorders with Anxiety in University Students
}

\author{
Denise Hollanda Iunes, ${ }^{1,2}$ Érika de Cássia Lopes Chaves, ${ }^{1,2}$ \\ Caroline de Castro Moura, ${ }^{1}$ Bruna Côrrea, ${ }^{1}$ Leonardo César Carvalho, ${ }^{1}$ \\ Andreia Maria Silva, ${ }^{1}$ and Emília Campos de Carvalho ${ }^{2}$
}

${ }^{1}$ Federal University of Alfenas, Alfenas, MG, Brazil

${ }^{2}$ University of São Paulo, Ribeirão Preto, SP, Brazil

Correspondence should be addressed to Denise Hollanda Iunes; deniseiunes@unifal-mg.edu.br

Received 27 March 2015; Accepted 21 April 2015

Academic Editor: Gerhard Litscher

Copyright (C) 2015 Denise Hollanda Iunes et al. This is an open access article distributed under the Creative Commons Attribution License, which permits unrestricted use, distribution, and reproduction in any medium, provided the original work is properly cited.

\begin{abstract}
Introduction. The aim of this study was to evaluate the role of auriculotherapy with mustard seeds in the treatment of temporomandibular disorders (TMDs), anxiety, and electromyographic (EMG) activity in university students. Methodology. The State Trait Anxiety Inventory (STAI), Research Diagnostic Criteria (RDC) for TMDs (RDC/TMDs), and electromyography were used in this study of 44 college students with high levels of anxiety and TMDs. The subjects were divided into two groups: an auriculotherapy (AA) group $(n=31)$ and an AA sham group $(n=13)$. The mustard seeds were applied to the shenmen, rim, sympathetic, brain stem, and temporomandibular joint (TMJ) points in the AA group and to sham points in the external ear and wrist in the AA sham group. The treatment protocol was 10 sessions (two treatments per week). Results. Anxiety $(p<0.01)$ was significantly reduced in the AA group. This group also showed a decrease in tender points in the mandibular posterior region $(p=0.04)$ and in the right side of the submandibular region $(p=0.02)$. Complaints of bilateral pain were reduced in the temporal tendon $(p \leq 0.01)$ and in the left side of the ATM $(p<0.01)$. In addition, electromyographic (EMG) activity was reduced during temporal muscle contraction $(p=0.03)$. Conclusion. Auriculotherapy was effective in the treatment of students with anxiety and TMDs.
\end{abstract}

\section{Introduction}

Temporomandibular disorders (TMDs) are one of the most common causes of orofacial complaints. They have multiple clinical manifestations, but the most frequent are pain in the region of the temporomandibular joint, pain and fatigue of the craniocervical muscles, especially those involved in mastication, limitation and deviations of mandibular movements, the presence of joint sounds [1], headaches, sensitivity to palpation of the masticatory muscles and temporomandibular joints [2], and tinnitus [3]. Given the variety of symptoms, TMDs have been attributed to multiple etiological factors [4], such as anatomical, functional, and psychosocial changes $[4,5]$. There is a lack of consensus on whether there is a relationship between anxiety, depression, and TMDs [4].
Pain relief is the main objective of primary therapeutic treatment of patients with TMDs. Treatment strategies include drugs to control chronic pain, physical therapy, surgery, and arthroscopy [6]. Dental approaches include occlusal intraoral devices and occlusal adjustment [7]. Psychosocial interventions [8] and low-frequency laser therapy have also been applied [9]. According to the literature, complementary and integrative practices are often used, in conjunction with conventional treatment $[6,10]$.

Auriculotherapy or ear acupuncture is a therapeutic acupuncture technique [11] which is based on the idea that pluripotent cell groups contain information on the whole organism and create regional organization centers, which represent different parts of the body, and that stimulation of a reflection point in the auricle for a sufficient duration 


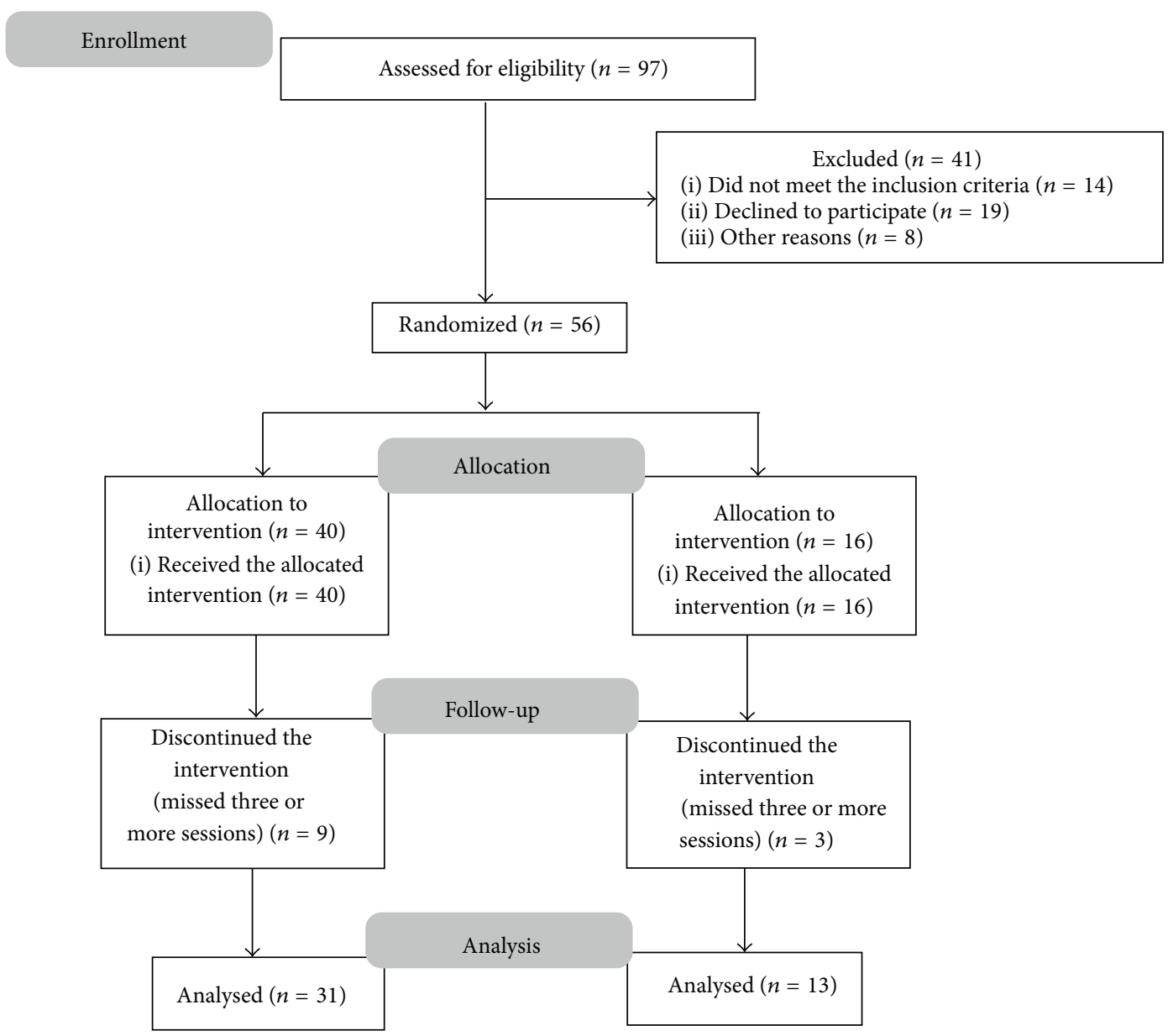

FIGURE 1: Flowchart of the participants.

TABLE 1: Pretreatment and posttreatment comparison of the mean anxiety profile according to the STAI-E in the AA group and sham AA group.

\begin{tabular}{|c|c|c|c|c|}
\hline Groups & $\begin{array}{r}\text { Pretreatment } \\
95\end{array}$ & $\begin{array}{l}\text { Posttreatment } \\
\text { CI }\end{array}$ & $p^{*}$ & $d$ \\
\hline $\begin{array}{l}\text { AA } \\
(n=31)\end{array}$ & $\begin{array}{c}53.26 \\
48.90-57.62 \\
\end{array}$ & $\begin{array}{c}45.60 \\
40.08-51.11 \\
\end{array}$ & $<0.01^{*}$ & $0.84^{* *}$ \\
\hline $\begin{array}{l}\text { Sham AA } \\
(n=13)\end{array}$ & $\begin{array}{c}48.20 \\
43.71-52.68\end{array}$ & $\begin{array}{c}47.00 \\
40.45-53.54\end{array}$ & $0.58^{*}$ & 0.11 \\
\hline
\end{tabular}

$d$ : effect size; ${ }^{*}$ paired $t$ test; ${ }^{* *}$ power $>80 \%$.

can relieve the symptoms of a disease [12]. Treatment with auriculotherapy is one of the most popular systemic microacupuncture techniques, with extensive applications [13].

Various studies have demonstrated the potential of auricular therapy in the treatment of a variety of conditions, such as its use in the treatment of TMDs [7] and its symptoms [14], especially pain [15]. Another study found that it improved the quality of life of individuals treated with traditional Chinese medicine (TCM), combined with conventional therapy [6].

Thus, the aim of this study was to evaluate the role of auricular acupuncture in the treatment of TMDs and anxiety in university students and the impact of the treatment on the electromyographic activity of various muscles.

\section{Methodology}

This controlled clinical, randomized, double-blind study was conducted with federal university students attending various health care courses (nursing, physiotherapy, pharmacy, and dentistry). A sociodemographic and clinical questionnaire was used to screen the students for major signs and symptoms of TMDs, such as headache, clicks, masticatory muscle pain, and TMJ pain. Ninety-seven students who reported signs and symptoms of TMDs were selected for the study.

The research was conducted over a 7-month period (October 2013 to May 2014). The inclusion criteria for this study were age being 18 years or over, availability for auriculotherapy sessions, and high levels of anxiety according to the State Trait Anxiety Inventory (STAI) [16]. The exclusion criteria were ear piercings (except a regular earring), inflammation, infection, or injury to the ear, receiving drug treatment for TMDs and anxiety, orofacial pain, or pregnancy.

Recruitment and enrollment of the participants is described in a trial flow diagram (Figure 1). Fifty-six volunteers fulfilled the eligibility criteria and were divided into two groups by simple randomization: an auriculotherapy 


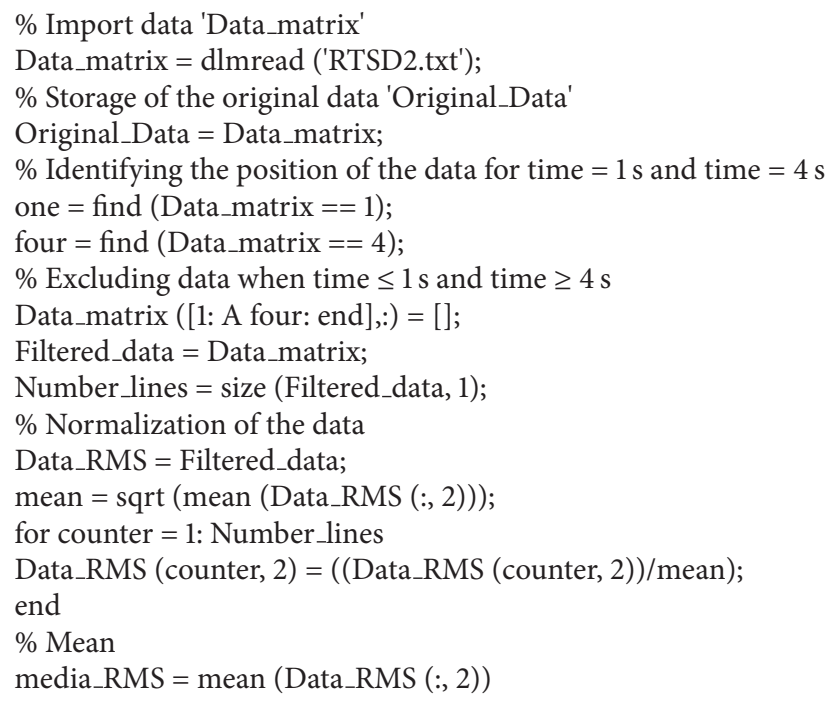

Algorithm 1: Algorithm used for normalization of the electromyography data.

group (AA) $(n=40)$ and a sham AA group $(n=16)$. During the intervention, some subjects dropped out. The postintervention reevaluation included 31 individuals in the AA group and 13 subjects in the sham AA group.

Fifty-six volunteers fulfilled the eligibility criteria and were evaluated at baseline and received a number. Then by a simple selection in a draw fewer volunteers were separated for the sham AA group $(n=16)$ and getting the other for the auriculotherapy group (AA) $(n=40)$.

The study subjects were evaluated before the first auriculotherapy session and after the 10th session by the same trained examiner who had no knowledge of the type of treatment applied. The instruments used in this evaluation were the STAI [16], I axis of the Research Diagnostic Criteria for TMDs (RDC/TMDs) [17], and surface electromyography (sEMG) measurements of the electrical activity of the bilateral trapezius, masseter, and temporal muscles.

The STAI was translated and adapted for the Portuguese language [18]. The STAI is composed of two parts, with 20 items for assessing trait anxiety and 20 for assessing state anxiety. The answers are scored on a Likert 4-point scale. The score ranges from 20 to 80 points, with $0-30$ indicating a low level of anxiety, 31-49 denoting a medium level of anxiety, and 50 or more indicating a high level of anxiety [16].

The RDC/TMDs allowed standardized assessment [17]. This instrument is divided into two axes. Axis I is the physical examination for the classification of subtypes of TMDs into three groups: muscle disorders (group Ia and Ib myofascial pain and myofascial pain with limited opening), disk displacement dysfunction (group II), and joint disorders (IIIa, arthralgia; IIIb, TMJ; and IIIc, osteoarthritis). The reliability of the RDC/TMDs was previously tested $[19,20]$, and the instrument was translated and validated officially for the Portuguese language [21]. To measure the intensity of pain in the evaluated points, we used a visual analog scale (VAS), where 0 was no pain and 10 denoted severe pain [7].
The EMG signals of the masseter and anterior temporal muscles were collected by disposable bipolar surface electrodes (Hal and Hal, São Paulo, Brazil). The EMG signals of the trapezius and reference muscles were collected using Meditrace monopolar electrodes with an $\mathrm{AgCl}$ catchment surface and a diameter of $10 \mathrm{~mm}$ (Tyco/Kendall, Mansfield, Canada). The monopolar electrodes were positioned parallel to each other at a distance of $20 \mathrm{~mm}$ center to center, along the fibers of the muscles described above, as prescribed earlier [22].

All the electromyography signals were captured with the EMG-Brazil Model 800C. In this model, six channels are configured to receive the EMG signals with a digital band-pass filter, a cutoff frequency of $20-500 \mathrm{~Hz}$, and final gain of 1000 times. Another channel is configured to receive signals from the load cell used for maximum voluntary isometric contraction. All the channels have a sampling frequency of $2000 \mathrm{~Hz}$. The system features specific software for signal acquisition and storage in data files. The EMG signals of the trapezius muscle were collected at rest, during isometric contraction (bilateral and unilateral) against gravity, and during maximum voluntary isometric contraction [23] using a load cell of $200 \mathrm{kgf}$. For the masseter and temporal muscles, the EMG signals were collected in the mandibular rest position and during maximal voluntary isometric contraction [24]. All the data were collected in triplicate while the subjects contracted their muscles for $10 \mathrm{sec}$, at intervals of $60 \mathrm{sec}$. In the analysis, we used the data collected during 2-7 sec. During the collection of the EMG data, the volunteers sat on a chair, with their feet flat on the floor. They rested their hands on their legs, with their shoulders relaxed and their head parallel to the Frankfurt line. They were directed to look straight ahead.

The EMG signals were processed with a specific algorithm, using programmed routines in MatLab software (Algorithm 1). Quantification of the signal was performed 
TABLE 2: Mobility evaluation of the mouth movements of the AA and sham AA groups pretreatment and posttreatment.

\begin{tabular}{|c|c|c|c|c|c|c|c|c|}
\hline \multirow[b]{2}{*}{ Mouth movements } & \multicolumn{2}{|c|}{$\mathrm{AA}(n=31)$} & \multirow[b]{2}{*}{$p^{*}$} & \multicolumn{5}{|c|}{ Sham AA $(n=13)$} \\
\hline & \multicolumn{2}{|c|}{$(95 \% \mathrm{CI})$} & & $d$ & \multicolumn{2}{|c|}{$(95 \% \mathrm{CI})$} & $p^{*}$ & $d$ \\
\hline Passive opening & $\begin{array}{c}36.50 \\
32.88-40.21\end{array}$ & $\begin{array}{c}38.30 \\
35.44-41.31 \\
\end{array}$ & 0.40 & 0.20 & $\begin{array}{c}37.30 \\
30.60-44.16 \\
\end{array}$ & $\begin{array}{c}38.40 \\
33.73-43.03 \\
\end{array}$ & 0.96 & 0.11 \\
\hline Maximum passive opening & $\begin{array}{c}50.90 \\
47.59-54.34 \\
\end{array}$ & $\begin{array}{c}51.00 \\
48.73-54.02 \\
\end{array}$ & 0.80 & 0.01 & $\begin{array}{c}49.00 \\
45.01-53.13\end{array}$ & $\begin{array}{c}52.50 \\
48.29-56.62 \\
\end{array}$ & $0.04^{*}$ & 0.51 \\
\hline Maximum active opening & $\begin{array}{c}47.60 \\
44.51-50.72\end{array}$ & $\begin{array}{c}47.00 \\
44.28-50.12\end{array}$ & 0.90 & 0.08 & $\begin{array}{c}46.30 \\
41.45-51.16\end{array}$ & $\begin{array}{c}49.50 \\
46.86-52.05\end{array}$ & 0.07 & 0.46 \\
\hline Overlap & $\begin{array}{c}3.50 \\
2.81-4.21 \\
\end{array}$ & $\begin{array}{c}3.40 \\
2.51-4.37 \\
\end{array}$ & 0.60 & 0.05 & $\begin{array}{c}5.40 \\
4.11-6.80 \\
\end{array}$ & $\begin{array}{c}4.20 \\
2.51-5.94\end{array}$ & 0.19 & 0.47 \\
\hline Right lateral deviation & $\begin{array}{c}8.40 \\
6.98-9.84 \\
\end{array}$ & $\begin{array}{c}8.20 \\
7.19-9.63\end{array}$ & 0.70 & 0.06 & $\begin{array}{c}7.50 \\
5.48-9.59 \\
\end{array}$ & $\begin{array}{c}9.20 \\
8.01-10.44 \\
\end{array}$ & 0.12 & 0.57 \\
\hline Left lateral deviation & $\begin{array}{c}8.70 \\
7.71-9.73 \\
\end{array}$ & $\begin{array}{c}7.86 \\
6.99-8.80 \\
\end{array}$ & 0.10 & 0.34 & $\begin{array}{c}7.40 \\
5.41-9.50 \\
\end{array}$ & $\begin{array}{c}8.50 \\
7.34-9.58 \\
\end{array}$ & 0.30 & 0.37 \\
\hline Protrusion & $\begin{array}{c}5.40 \\
4.37-6.59 \\
\end{array}$ & $\begin{array}{c}4.80 \\
3.76-5.95\end{array}$ & 0.20 & 0.21 & $\begin{array}{c}6.40 \\
5.31-7.60 \\
\end{array}$ & $\begin{array}{c}6.20 \\
5.44-7.01 \\
\end{array}$ & 0.70 & 0.12 \\
\hline
\end{tabular}

$d$ : effect size; ${ }^{*}$ Wilcoxon test.

by RMS amplitude, as recommended to evaluate the level of muscle activity [25].

We established a protocol to determine the application of the points in the auriculotherapy. The protocol was based on personal clinical experience, the Standards for Reporting Interventions in Clinical Trials of Acupuncture [26], and the literature $[27,28]$. The protocol was later submitted for refining to four judges with 2-10 years of accreditation and experience in auriculotherapy. Interventionists had training in auriculotherapy and at least two years of experience in the area.

The auriculotherapy used mustard seeds, which were attached to the skin with Micropore tape. Each volunteer underwent 10 sessions, twice a week (Monday and Thursday) for 6 weeks, with an alternate ear used each application. Prior to the placement of the mustard seeds, the subject's ear was cleaned with $70 \%$ ethyl alcohol. During the placement of the seeds, the volunteer remained sitting on a chair with a back support. As a constant pressure stimulus on the point is needed for the intervention to have the expected effect, the volunteer was instructed to press each auricular point at least 5 times a day, applying pressure for $1 \mathrm{~min}$ to every point [29] or until the pressure produced localized pain or discomfort [30]. The AA group received five points per subject per session being the shenmen, kidney, sympathetic, brain stem [27, 28], and TMJ [27]. These points have sedative and tranquilizer effects [11, 27, 31]. The sham AA group received two points per subject per session being the wrist and external ear [27, 28] (Figure 2). These points were chosen because they were far from the group of points the AA group.

The Statistical Package for the Social Sciences (SPSS), version 23.0, was used for the statistical analysis. The ShapiroWilk normality test was performed, followed by a $t$-test for data with a normal distribution and a Wilcoxon and MannWhitney test for data with a nonnormal distribution. The significance level was $5 \%$. The effect size and the power effect of the sample were calculated with GPower 3.1.7 software (Franz Faut, Universität Kiel Germany, 2008). A small effect

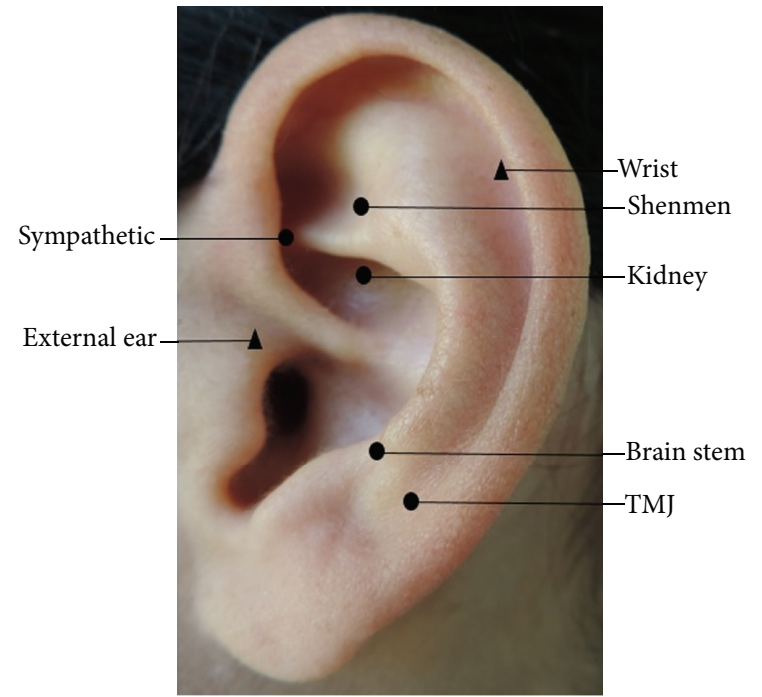

FIGURE 2: Auricular points used in the intervention: AA group (circle) and sham AA group (triangle). These points were used in the right and left ears alternately.

size $(d)$ was considered $0.20 \leq d<0.50$, a medium effect size was considered $0.50 \leq d<0.80$, and a large effect size was considered $d \geq 0.80$. In the power analysis, more than 0.80 was needed to denote adequate power [32].

This study was approved by the Research Ethics Committee of the Federal University of Alfenas (Protocol number: 164 590), and it was registered with the Brazilian Registry of Clinical Trials Platform (Protocol number: U111-11473083). The volunteers received information regarding their participation in this research study and they signed free and informed consent documents.

\section{Results}

Forty-four college students participated in this study: 31 were assigned to the AA group and 13 were in the sham AA 
TABLE 3: Pretreatment and posttreatment comparison of the tender points of the AA and sham AA groups based on the RDC/TMDs and the electromyographic activity of the trapezius muscle.

\begin{tabular}{|c|c|c|c|c|c|c|c|c|c|c|}
\hline \multirow[b]{2}{*}{ Points } & \multicolumn{2}{|c|}{$\mathrm{AA}(n=31)$} & \multicolumn{6}{|c|}{ Sham AA $(n=13)$} & \multicolumn{2}{|c|}{ Intergroup } \\
\hline & $\begin{array}{r}\text { Pretreatment } \\
(95\end{array}$ & $\begin{array}{l}\text { Posttreatment } \\
0 \mathrm{CI})\end{array}$ & $p$ & $d$ & $\begin{array}{r}\text { Pretreatment } \\
(95\end{array}$ & $\begin{array}{l}\text { Posttreatment } \\
6 \text { CI) }\end{array}$ & $p$ & $d$ & $\begin{array}{l}\text { Before } \\
(p)\end{array}$ & $\begin{array}{c}\text { After } \\
(p)\end{array}$ \\
\hline \multicolumn{11}{|c|}{ Right temporal } \\
\hline A & $\begin{array}{c}1.20 \\
0.47-1.93\end{array}$ & $\begin{array}{c}0.93 \\
0.24-1.62\end{array}$ & 0.45 & 0.15 & $\begin{array}{c}1.34 \\
0.04-2.72\end{array}$ & $\begin{array}{c}1.77 \\
0.98-2.55\end{array}$ & 0.51 & 0.22 & 0.64 & 0.01 \\
\hline M & $\begin{array}{c}1.00 \\
0.20-1.79\end{array}$ & $\begin{array}{c}0.86 \\
0.17-1.54\end{array}$ & 0.57 & 0.67 & $\begin{array}{c}0.85 \\
-0.07-1.76\end{array}$ & $\begin{array}{c}1.08 \\
0.44-1.70\end{array}$ & 0.76 & 0.17 & 0.79 & 0.16 \\
\hline $\mathrm{P}$ & $\begin{array}{c}0.96 \\
0.28-1.64\end{array}$ & $\begin{array}{c}0.86 \\
0.17-1.54\end{array}$ & 0.66 & 0.06 & $\begin{array}{c}0.85 \\
-0.07-1.76\end{array}$ & $\begin{array}{c}0.77 \\
0.15-1.38\end{array}$ & 0.74 & 0.06 & 0.95 & 0.60 \\
\hline \multicolumn{11}{|c|}{ Left temporal } \\
\hline $\mathrm{A}$ & $\begin{array}{c}1.00 \\
0.14-1.85\end{array}$ & $\begin{array}{c}0.76 \\
0.21-1.30\end{array}$ & 0.51 & 0.12 & $\begin{array}{c}2.15 \\
0.65-3.65\end{array}$ & $\begin{array}{c}1.23 \\
0.61-1.84\end{array}$ & 0.20 & 0.41 & 0.03 & 0.07 \\
\hline M & $\begin{array}{c}0.93 \\
0.19-1.66\end{array}$ & $\begin{array}{c}0.82 \\
0.27-1.37\end{array}$ & 0.54 & 0.06 & $\begin{array}{c}1.00 \\
0.07-1.92\end{array}$ & $\begin{array}{c}1.31 \\
0.40-2.21\end{array}$ & 0.32 & 0.21 & 0.40 & 0.20 \\
\hline $\mathrm{P}$ & $\begin{array}{c}0.76 \\
0.02-1.49\end{array}$ & $\begin{array}{c}0.75 \\
0.21-1.30\end{array}$ & 0.93 & 0.01 & $\begin{array}{c}1.15 \\
0.23-2.07\end{array}$ & $\begin{array}{c}0.92 \\
2.29-1.55\end{array}$ & 0.53 & 0.17 & 0.09 & 0.34 \\
\hline \multicolumn{11}{|c|}{ Right masseter } \\
\hline $\mathrm{O}$ & $\begin{array}{c}2.96 \\
1.99-3.93\end{array}$ & $\begin{array}{c}1.69 \\
0.90-2.47\end{array}$ & 0.06 & 0.54 & $\begin{array}{c}2.38 \\
0.99-3.77\end{array}$ & $\begin{array}{c}1.85 \\
0.83-2.85\end{array}$ & 0.32 & 0.26 & 0.50 & 0.48 \\
\hline B & $\begin{array}{c}2.58 \\
1.73-3.43\end{array}$ & $\begin{array}{c}1.62 \\
0.85-2.38\end{array}$ & 0.10 & 0.45 & $\begin{array}{c}3.08 \\
1.48-4.66\end{array}$ & $\begin{array}{c}2.23 \\
1.15-3.31\end{array}$ & 0.37 & 0.37 & 0.60 & 0.20 \\
\hline I & $\begin{array}{c}1.58 \\
0.68-2.48\end{array}$ & $\begin{array}{c}1.00 \\
0.44-1.55\end{array}$ & 0.29 & 0.23 & $\begin{array}{c}4.08 \\
2.52-5.62\end{array}$ & $\begin{array}{c}1.70 \\
0.63-2.75\end{array}$ & $0.01^{*}$ & 1.05 & $<0.01$ & 0.17 \\
\hline \multicolumn{11}{|c|}{ Left masseter } \\
\hline $\mathrm{O}$ & $\begin{array}{c}3.10 \\
2.01-4.19\end{array}$ & $\begin{array}{c}1.96 \\
1.16-2.76\end{array}$ & 0.08 & 0.44 & $\begin{array}{c}1.92 \\
0.51-3.32\end{array}$ & $\begin{array}{c}2.31 \\
1.06-3.55\end{array}$ & 0.51 & 0.18 & 0.22 & 0.55 \\
\hline B & $\begin{array}{c}2.72 \\
1.77-3.67\end{array}$ & $\begin{array}{c}2.10 \\
1.26-2.93\end{array}$ & 0.25 & 0.26 & $\begin{array}{c}2.31 \\
1.06-3.55\end{array}$ & $\begin{array}{c}2.08 \\
0.96-3.19\end{array}$ & 0.68 & 0.12 & 0.71 & 0.95 \\
\hline I & $\begin{array}{c}1.58 \\
0.63-2.53\end{array}$ & $\begin{array}{c}1.76 \\
0.78-2.73\end{array}$ & 0.82 & 0.07 & $\begin{array}{c}3.54 \\
2.10-4.96\end{array}$ & $\begin{array}{c}2.61 \\
1.52-3.70\end{array}$ & 0.17 & 0.43 & $<0.01$ & 0.07 \\
\hline \multicolumn{11}{|c|}{ Posterior mandibular region } \\
\hline $\mathrm{R}$ & $\begin{array}{c}5.00 \\
4.00-5.99\end{array}$ & $\begin{array}{c}3.44 \\
2.54-4.35\end{array}$ & $0.04^{*}$ & 0.62 & $\begin{array}{c}4.84 \\
3.21-6.47\end{array}$ & $\begin{array}{c}7.08 \\
6.20-7.94\end{array}$ & $0.03^{*}$ & 0.96 & 0.85 & 0.00 \\
\hline $\mathrm{L}$ & 4.69 & $\begin{array}{c}4.34 \\
3.15-5.53\end{array}$ & 0.33 & 0.11 & $\begin{array}{c}3.85 \\
2.15-5.53\end{array}$ & $\begin{array}{c}6.38 \\
5.40-7.32\end{array}$ & $0.01^{*}$ & 1.04 & 0.37 & 0.05 \\
\hline \multicolumn{11}{|c|}{ Submandibular region } \\
\hline $\mathrm{R}$ & $\begin{array}{c}5.07 \\
3.87-6.26\end{array}$ & $\begin{array}{c}3.07 \\
2.14-3.99\end{array}$ & $0.02^{*}$ & 0.70 & $\begin{array}{c}5.38 \\
3.70-7.06\end{array}$ & $\begin{array}{c}5.77 \\
4.20-7.33\end{array}$ & 0.72 & 0.14 & 0.90 & $<0.01$ \\
\hline $\mathrm{L}$ & $\begin{array}{c}5.00 \\
3.91-3.08\end{array}$ & $\begin{array}{c}4.21 \\
3.32-5.08\end{array}$ & 0.14 & 0.30 & $\begin{array}{c}5.38 \\
3.54-7.22\end{array}$ & $\begin{array}{c}5.54 \\
3.85-7.22\end{array}$ & 0.92 & 0.05 & 0.66 & 0.11 \\
\hline \multicolumn{11}{|c|}{ Lateral pterygoid } \\
\hline $\mathrm{R}$ & $\begin{array}{c}3.65 \\
2.64-4.66\end{array}$ & $\begin{array}{c}2.45 \\
1.47-3.42\end{array}$ & 0.09 & 0.46 & $\begin{array}{c}2.08 \\
0.25-3.89\end{array}$ & $\begin{array}{c}1.23 \\
0.09-2.36\end{array}$ & 0.18 & 0.32 & 0.06 & 0.09 \\
\hline $\mathrm{L}$ & $\begin{array}{c}2.00 \\
1.01-2.98\end{array}$ & $\begin{array}{c}2.51 \\
1.51-3.51\end{array}$ & 0.42 & 0.20 & $\begin{array}{c}2.69 \\
0.80-4.57\end{array}$ & $\begin{array}{c}1.85 \\
0.45-3.23\end{array}$ & 0.45 & 0.30 & 0.55 & 0.44 \\
\hline \multicolumn{11}{|c|}{ Temporal tendon } \\
\hline $\mathrm{R}$ & $\begin{array}{c}4.93 \\
3.85-6.01\end{array}$ & $\begin{array}{c}2.96 \\
2.04-3.88\end{array}$ & $0.01^{*}$ & 0.74 & $\begin{array}{c}5.31 \\
3.86-6.75\end{array}$ & $\begin{array}{c}4.30 \\
2.79-5.81\end{array}$ & 0.17 & 0.41 & 0.77 & 0.11 \\
\hline $\mathrm{L}$ & $\begin{array}{c}4.55 \\
3.46-5.63\end{array}$ & $\begin{array}{c}2.31 \\
1.34-3.27\end{array}$ & $<0.01^{*}$ & 0.83 & $\begin{array}{c}5.46 \\
4.21-6.71\end{array}$ & $\begin{array}{c}3.67 \\
2.00-5.53\end{array}$ & 0.06 & 0.69 & 0.38 & 0.10 \\
\hline \multicolumn{11}{|c|}{ Side portion TMJ } \\
\hline $\mathrm{R}$ & $\begin{array}{c}3.52 \\
2.53-4.50\end{array}$ & $\begin{array}{c}3.17 \\
2.10-4.24\end{array}$ & 0.48 & 0.13 & $\begin{array}{c}3.08 \\
1.86-5.97\end{array}$ & $\begin{array}{c}2.92 \\
3.20-6.33\end{array}$ & 0.79 & 0.06 & 0.79 & 0.06 \\
\hline $\mathrm{L}$ & $\begin{array}{c}3.34 \\
0.96-1.86\end{array}$ & $\begin{array}{c}1.41 \\
0.68-2.21\end{array}$ & $<0.01^{*}$ & 0.80 & $\begin{array}{c}4.46 \\
2.63-6.68\end{array}$ & $\begin{array}{c}4.61 \\
2.91-6.31\end{array}$ & 0.83 & 0.05 & $<0.01$ & 0.17 \\
\hline
\end{tabular}


TABLE 3: Continued.

\begin{tabular}{|c|c|c|c|c|c|c|c|c|c|c|}
\hline \multirow[b]{2}{*}{ Points } & \multicolumn{2}{|c|}{$\mathrm{AA}(n=31)$} & \multicolumn{6}{|c|}{ Sham AA $(n=13)$} & \multicolumn{2}{|c|}{ Intergroup } \\
\hline & \multicolumn{2}{|c|}{$(95 \% \mathrm{CI})$} & $p$ & $d$ & $\begin{array}{r}\text { Pretreatment } \\
(95\end{array}$ & $\begin{array}{l}\text { Posttreatment } \\
\text { CI) }\end{array}$ & $p$ & $d$ & $\begin{array}{l}\text { Before } \\
(p)\end{array}$ & $\begin{array}{c}\text { After } \\
(p)\end{array}$ \\
\hline \multicolumn{11}{|c|}{ Back of the TMJ } \\
\hline $\mathrm{R}$ & $\begin{array}{c}1.83 \\
1.05-2.59\end{array}$ & $\begin{array}{c}1.45 \\
2.29-4.39\end{array}$ & 0.70 & 0.19 & $\begin{array}{c}3.92 \\
1.22-4.93\end{array}$ & $\begin{array}{c}4.77 \\
1.43-4.41\end{array}$ & 0.44 & 0.28 & 0.26 & 0.04 \\
\hline $\mathrm{L}$ & $\begin{array}{c}0.62 \\
0.34-0.89\end{array}$ & $\begin{array}{c}0.93 \\
0.31-1.54\end{array}$ & 0.64 & 0.22 & $\begin{array}{c}3.00 \\
1.23-4.76\end{array}$ & $\begin{array}{c}1.77 \\
0.32-3.21\end{array}$ & 0.07 & 0.46 & $<0.01$ & 0.18 \\
\hline \multicolumn{11}{|c|}{ Trapezius } \\
\hline $\mathrm{R}$ & $\begin{array}{c}5.03 \\
3.85-6.21\end{array}$ & $\begin{array}{c}4.17 \\
3.09-5.25\end{array}$ & 0.16 & 0.29 & $\begin{array}{c}5.00 \\
3.08-6.91\end{array}$ & $\begin{array}{c}6.23 \\
4.61-7.85\end{array}$ & 0.22 & 0.42 & 0.88 & 0.03 \\
\hline $\mathrm{L}$ & $\begin{array}{c}4.03 \\
2.93-5.30\end{array}$ & $\begin{array}{c}3.89 \\
2.74-5.04\end{array}$ & 0.78 & 0.05 & $\begin{array}{c}3.23 \\
1.30-5.16\end{array}$ & $\begin{array}{c}5.77 \\
4.03-7.49\end{array}$ & $0.02^{*}$ & 0.84 & 0.38 & 0.06 \\
\hline
\end{tabular}

A: anterior; M: middle; P: posterior; O: origin; B: belly; I: insertion; R: right; L: left; $d$ : effect size; ${ }^{*}$ Wilcoxon test; intergroup analysis: Mann-Whitney test.

group. In the AA group, 93.55\% $(n=28)$ were women, and $9.67 \%(n=3)$ were men. The mean \pm SD age of the study participants was $21.61 \pm 3.27$ years. In the sham AA, $100 \%$ $(n=13)$ of the subjects were women, and the mean \pm SD age of the study participants was $20.87 \pm 1.50$ years. According to the RDC/TMDs, all the participants were classified as category Ia. In the AA group and sham AA group, 33\% and $15.38 \%$ of subjects, respectively, were also classified as having a category IIIa TMD. In the AA group, the anxiety state of the subjects was significantly reduced after the application of auriculotherapy (Table 1).

The results of the evaluation of the mobility of mouth movements using the RDC/TMD are shown in Table 2. No statistically significant changes were identified, even in the maximal passive opening movement in the sham AA group. Although the values of maximum passive mouth opening were significant, it exhibited a low power and a moderate effect size. In the initial assessment of both groups, none of the subjects had limitations in the evaluated movements.

The RDC/TMDs were used to evaluate the tender points of the masticatory muscles and TMJs and palpation of the trapezius muscle. The results are shown in Table 3. In the AA group, pain was significantly reduced in the five points assessed, together with a high power and medium to high effect size. The other points showed clinical improvement. In the sham AA group, $46 \%$ of those evaluated reported increased pain at the evaluated points, with statistical significance.

Table 4 shows the comparison of the intragroup and intergroup analyses of the EMG activity in the AA and sham AA groups. Only the bilateral contraction of the temporalis muscle in the AA group showed a significant difference between the pre- and postintervention, with a low power effect. However, in the posttreatment intergroup analysis, the EMG activity of the trapezius and temporalis muscles at rest and during contraction showed statistical significance.

\section{Discussion}

In TCM, disease is seen as an imbalance in the meridians. Therefore, the processing based on this analysis has the potential to provide a strategy for overall system management for TMDs [6], mainly with a view to reduce pain [33] and anxiety [11]. As noted previously, there is a need for different studies to find common auricular acupuncture points to create an international standard of clinical research that facilitates replication and dissemination of the results [13]. The establishment of the protocol for the treatment of TMDs in this study can aid this goal, although further multicenter, longitudinal studies with larger samples are needed in this area.

In the present study, auriculotherapy significantly reduced anxiety and provided pain relief. It also reduced the electrical activity of the trapezius and temporal muscles. Anxiety can contribute to the development of a TMD or be the result of this disorder and its perpetuation [34]. In this study, all the volunteers with high levels of anxiety had TMDs. Other researchers also observed a reduction in anxiety after auriculotherapy [11, 35, 36], pointing to the potential of this technique in the control of various clinical conditions.

Anxiety is an increasingly common disorder in people's lives today [37]. It is treated with anxiolytic psychotropic drugs, often at the request of the patient leading to unnecessary and inappropriate treatment [38]. The use of integrative/complementary treatments, including auriculotherapy, has been investigated to reduce the dependence on such drugs. The former can be integrated with traditional therapy or even replace it, as integrative/complementary treatments do not have side effects. They are also inexpensive and easy to administer.

TMD-related pain can be chronic, with the dysfunction affecting not only peripheral nervous system, but also the central nervous system, thereby producing a widespread perception of pain [39]. This type of pain is often difficult to treat and is accompanied by emotional components, such as anxiety and/or depression. The symptoms of anxiety are strongly related to muscle pain [40]. Joint symptoms were also observed in the present study.

The goal of all TMD treatment is to minimize pain. In the present study, the therapy was effective in reducing pain, with statistical significance for five of the points assessed. The findings corroborate those of an earlier study [7], which demonstrated the contribution of Eastern therapies in 
TABLE 4: Results of the intragroup and intergroup analysis of the EMG activity of the AA group and sham AA group.

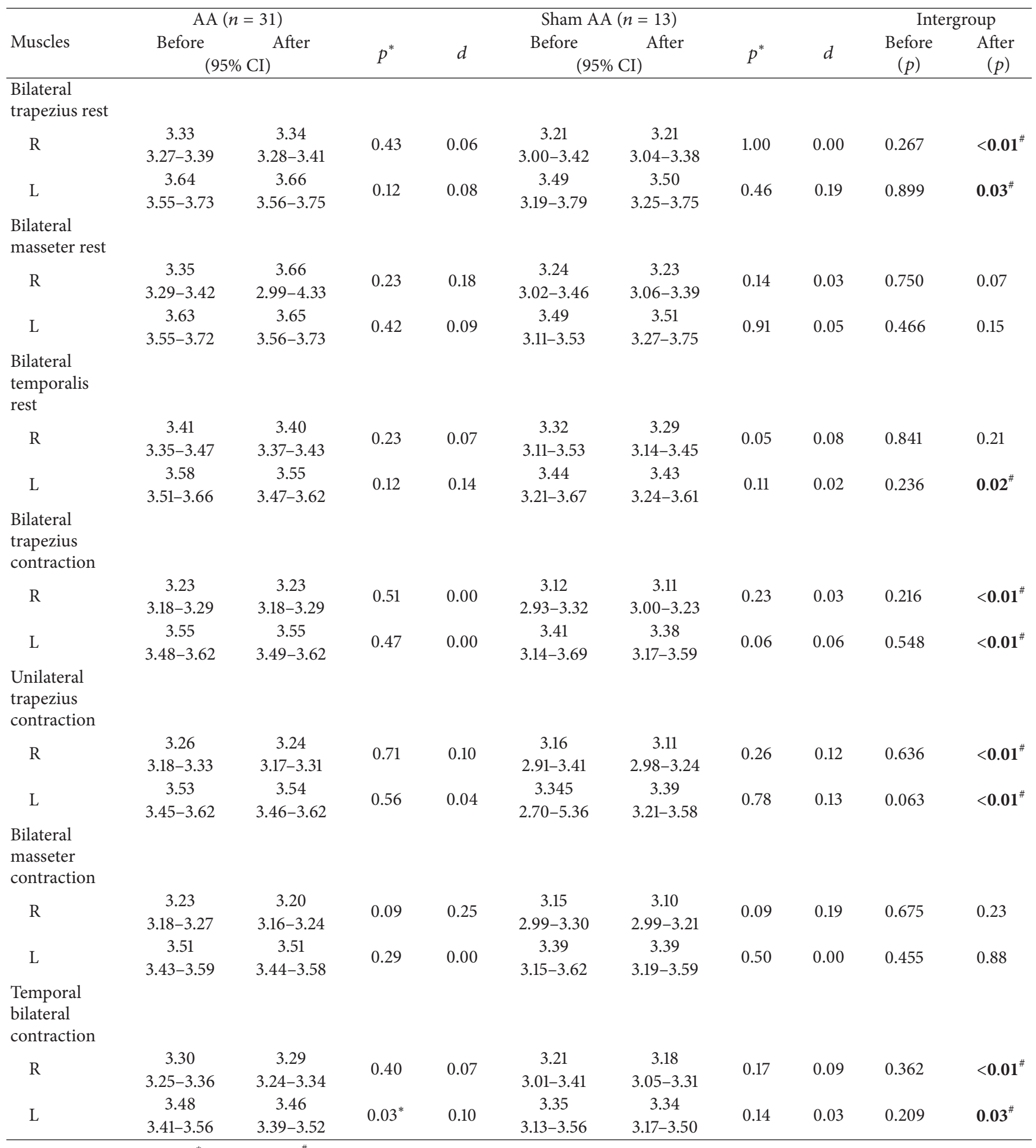

R: right; L: left; $d$ : effect size; ${ }^{*}$ Wilcoxon test; ${ }^{*}$ Mann-Whitney test.

decreasing TMD-related pain. Treatments for TMDs must act in a holistic manner, both on the physical and emotional symptoms. In the current study, anxiety and pain were significantly reduced in the subjects who received auriculotherapy. In addition, the electrical activity of the muscles was significantly reduced in the intergroup analysis.
The anxiety and pain associated with TMDs can trigger hyperactivity and altered muscle mechanics, which can perpetuate the muscle pain [41]. Therefore, a muscle evaluation is important to establish the diagnosis and treatment of TMDs. In many cases, TMDs may cause inflammation of the joints, followed by biomechanical changes, which give 
rise to pain in the affected region. A previous study found that TMDs may be related to abnormal processing of pain in the trigeminal system [41]. Other studies pointed to the relationship between mastigatory and cervical muscle tenderness associated emotional changes $[42,43]$. They found that this resulted in emotional changes, which predisposed individuals to orofacial pain and TMDs [42, 43]. In the current study, the efficacy of the treatment was assessed by evaluating the presence of pain in both groups and the EMG activity. The treatment was effective, as shown by the improvement in tender points and the electrical activity of the trapezius muscle over time in the intergroup analysis. Therefore, it is believed that the auriculotherapy may have served as a mechanism of muscle modulatory activity, as reported previously [34].

A previous study reported that anxiety and stress contributed to the development of TMDs and that it increased the recruitment of the anterior temporal muscle, sternocleidomastoid, and upper trapezius, in addition to the excitability of the trigeminal-neck reflex, causing pain and trigger points in the muscles, leading to a vicious cycle [44]. In the present study, after the intervention, the EMG activity of the descending trapezius and anterior temporal decreased during maximal muscle contraction. The reduction in the EMG activity of the temporal muscle was significant in the AA group but not in the sham AA group. No changes in EMG activity were observed in the masseter muscle. A previous study reported that the EMG activity of the descending fibers of the trapezius did not change in individuals without a history of masticatory system dysfunction during maximal effort centric occlusion of the jaw [23]. The lack of EMG activity reported in the previous study explains why anxiety and stress can lead to the development of a vicious cycle that contributes to hyperactivity of the masticatory muscles in adolescents with severe TMD symptoms [24].

The between-group comparison revealed a reduction in EMG activity at rest and during muscle contraction. This reduction in EMG activity may be related to the effect of the auriculotherapy that was observed after the intervention, as auriculotherapy stimulates the peripheral nervous system by promoting local and systemic reflex responses $[45,46]$. These responses are mediated by the release of endorphins, serotonin, and noradrenaline released from the endocrine system, immune system, and higher centers in the central control of pain $[45,46]$.

Study Limitation. The limitations of this study were the small sample size, absence of follow-up, and absence of a control group.

\section{Conclusion}

Auriculotherapy helped to reduce anxiety and tender points in the posterior region right mandibular and submandibular, tendon bilateral temporalis, and left TMJ. It also reduced EMG activity during temporal muscle contraction.

\section{Conflict of Interests}

The authors declare no conflict of interests.

\section{Acknowledgment}

This work was carried out with the financial support of The National Council of Technological and Scientific Development (Process nos. 477383/2012-2 and 401126/2013-7).

\section{References}

[1] M. Schmid-Schwap, M. Bristela, M. Kundi, and E. Piehslinger, "Sex-specific differences in patients with temporomandibular disorders," Journal of Orofacial Pain, vol. 27, no. 1, pp. 27-42, 2013.

[2] S. B. Graff-Radford and J. P. Bassiur, "Temporomandibular disorders and headaches," Neurologic Clinics, vol. 32, no. 2, pp. 525-537, 2014.

[3] O. Bernhardt, T. Mundt, A. Welk et al., "Signs and symptoms of temporomandibular disorders and the incidence of tinnitus," Journal of Oral Rehabilitation, vol. 38, no. 12, pp. 891-901, 2011.

[4] N. N. Giannakopoulos, L. Keller, P. Rammelsberg, K.-T. Kronmüller, and M. Schmitter, "Anxiety and depression in patients with chronic temporomandibular pain and in controls," Journal of Dentistry, vol. 38, no. 5, pp. 369-376, 2010.

[5] N. J. Nassif, F. Al-Salleeh, and M. Al-Admawi, "The prevalence and treatment needs of symptoms and signs of temporomandibular disorders among young adult males," Journal of Oral Rehabilitation, vol. 30, no. 9, pp. 944-950, 2003.

[6] C. Ritenbaugh, R. Hammerschlag, S. F. Dworkin et al., "Comparative effectiveness of traditional chinese medicine and psychosocial care in the treatment of temporomandibular disorders-associated chronic facial pain," Journal of Pain, vol. 13, no. 11, pp. 1075-1089, 2012.

[7] Y. F. Huang, J. C. Lin, H. W. Yang, Y. H. Lee, and C. H. Yu, "Clinical effectiveness of laser acupuncture in the treatment of temporomandibular joint disorder," Journal of the Formosan Medical Association, vol. 113, no. 8, pp. 535-539, 2014.

[8] W. Jerjes, T. Upile, S. Abbas et al., "Muscle disorders and dentition-related aspects in temporomandibular disorders: controversies in the most commonly used treatment modalities," International Archives of Medicine, vol. 1, no. 1, article 23, pp. 1-13, 2008.

[9] M. O. Mazzetto, T. G. Carrasce, E. F. Bidinelo, R. C. A. Pizzo, and R. G. Mazzetto, "Low intensity laser application in temporomandibular disorders: a phase I double-blind study," Cranio: The Journal of Craniomandibular Practice, vol. 25, no. 3, pp. 186-192, 2007.

[10] A. Jung, B.-C. Shin, M. S. Lee, H. Sim, and E. Ernst, "Acupuncture for treating temporomandibular joint disorders: a systematic review and meta-analysis of randomized, sham-controlled trials," Journal of Dentistry, vol. 39, no. 5, pp. 341-350, 2011.

[11] J. M. do Prado, L. F. S. Kurebayashi, and M. J. P. da Silva, "Auriculotherapy effectiveness in the reduction of anxiety in nursing students," Revista da Escola de Enfermagem, vol. 46, no. 5, pp. 1200-1206, 2012.

[12] L. Gori and F. Firenzuoli, "Ear acupuncture in European traditional medicine," Evidence-Based Complementary and Alternative Medicine, vol. 4, no. 1, pp. 13-16, 2007. 
[13] L. Wang, B. Zhao, and L. Zhou, "Status and strategies analysis on international standardization of auricular acupuncture points," Journal of Traditional Chinese Medicine, vol. 33, no. 3, pp. 408412, 2013.

[14] C.-B. Ahn, S.-J. Lee, J.-C. Lee, J. P. J. Fossion, and A. Sant'Ana, “A clinical pilot study comparing traditional acupuncture to combined acupuncture for treating headache, trigeminal neuralgia and retro-auricular pain in facial palsy," Journal of Acupuncture and Meridian Studies, vol. 4, no. 1, pp. 29-43, 2011.

[15] K. M. Hedayat, "New therapy providing pain relief to some patients," Explore, vol. 4, no. 4, pp. 228-231, 2008.

[16] R. Andreatini and M. L. Seabra, "The stability of STAI-trait portion over 5 years period," Revista ABP-APAL, vol. 14, no. 1, pp. 21-25, 1993.

[17] S. F. Dworkin and L. LeResche, "Research diagnostic criteria for temporomandibular disorders: review, criteria, examinations and specifications, critique," Journal of Craniomandibular Disorders: Facial \& Oral Pain, vol. 6, no. 4, pp. 301-355, 1992.

[18] A. M. B. Biaggio and L. F. S. Natalicio, Manual for the State-Trait Anxiety Inventory (STAI): Translation and Adaptation, Centro Editor de Psicologia Aplicada, Rio de Janeiro, Brazil, 1979.

[19] M. T. John, S. F. Dworkin, and L. A. Mancl, "Reliability of clinical temporomandibular disorder diagnoses," Pain, vol. 118, no. 1-2, pp. 61-69, 2005.

[20] M. Schmitter, B. Ohlmann, M. T. John, C. Hirsch, and P. Rammelsberg, "Research diagnostic criteria for temporomandibular disorders: a calibration and reliability study," Cranio, vol. 23, no. 3, pp. 212-218, 2005.

[21] F. J. Pereira Jr., E. E. Favilla, S. Dworkin, and K. Huggins, "Research diagnostic criteria for temporomandibular disorders (RDC/TMD): formal translation to Portuguese," Jornal Brasileiro de Clinica Odontologica Integrada, vol. 8, no. 47, pp. 384-395, 2004.

[22] Seniam Project, "Surface electromyography for the non-invasive assessment of muscles," 2012, http://www.seniam.org/.

[23] F. Politti, C. F. Amorim, L. H. Sales Oliveira, F. D. Guerra, I. L. Souza Pieres, and E. T. Palomari, "Maximal clenching effort influence on the electromyographic activity of the trapezius muscle in healthy subjects," Journal of Bodywork and Movement Therapies, vol. 14, no. 4, pp. 346-351, 2010.

[24] L. Lauriti, P. F. Silva, F. Politti et al., "Pattern of electromyographic activity in mastication muscles of adolescents with temporomandibular disorder," Journal of Physical Therapy Science, vol. 25, no. 10, pp. 1303-1307, 2013.

[25] C. J. De Luca, "The use of surface electromyography in biomechanics," Journal of Applied Biomechanics, vol. 13, no. 2, pp. 135$163,1997$.

[26] H. Macpherson, D. G. Altman, R. Hammerschlag et al., "STRICTA revision group. Revised standards for reporting interventions in clinical trials of acupuncture (STRICTA): extending the CONSORT statement," Journal of Evidence-Based Medicine, vol. 3, no. 3, pp. 140-155, 2010.

[27] M. Romoli, "Ear acupuncture: historical abstract-differences of ear cartography between the east and the west," Deutsche Zeitschrift für Akupunktur, vol. 53, no. 4, pp. 24-33, 2010.

[28] World Federation of Acupuncture-Moxibustion Societies (WFAS), "Auricular acupuncture point (WFAS STANDARD002: 2012)," World Journal of Acupuncture-Moxibustion, vol. 23, no. 3, pp. 12-21, 2013.

[29] A. P. Zanelatto, "Evaluation of ear acupressure on painful shouder syndrome: case study," Revista Brasileira de Enfermagem, vol. 66, no. 5, pp. 694-701, 2013.
[30] F. Qu, D. Zhang, L.-T. Chen et al., "Auricular acupressure reduces anxiety levels and improves outcomes of in vitro fertilization: a prospective, randomized and controlled study," Scientific Reports, vol. 4, article 5028, 2014.

[31] S.-M. Wang and Z. N. Kain, "Auricular acupuncture: a potential treatment for anxiety," Anesthesia and Analgesia, vol. 92, no. 2, pp. 548-553, 2001.

[32] J. Cohen, "The concepts of power analysis," in Statistical Power Analysis for the Behavioral Sciences, J. Cohen, Ed., pp. 1-7, Academic Press, Hillsdale, NJ, USA, 1988.

[33] R. La Touche, G. Goddard, J. L. De-La-Hoz et al., "Acupuncture in the treatment of pain in temporomandibular disorders: a systematic review and meta-analysis of randomized controlled trials," Clinical Journal of Pain, vol. 26, no. 6, pp. 541-550, 2010.

[34] D. R. Monteiro, P. R. J. Zuim, A. A. Pesqueira, P. D. P. Ribeiro, and A. R. Garcia, "Relationship between anxiety and chronic orofacial pain of temporomandibular disorder in a group of university students," Journal of Prosthodontic Research, vol. 55, no. 3, pp. 154-158, 2011.

[35] R. Barker, A. Kober, K. Hoerauf et al., "Out-of-hospital auricular acupressure in elder patients with hip fracture: a randomized double-blinded trial," Academic Emergency Medicine, vol. 13, no. 1, pp. 19-23, 2006.

[36] M. Karst, M. Winterhalter, S. Münte et al., "Auricular acupuncture for dental anxiety: a randomized controlled trial," Anesthesia and Analgesia, vol. 104, no. 2, pp. 295-300, 2007.

[37] L. H. Andrade, Y.-P. Wang, S. Andreoni et al., "Mental disorders in megacities: findings from the São Paulo megacity mental health survey, Brazil," PLoS ONE, vol. 7, no. 2, Article ID e31879, 11 pages, 2012.

[38] B. A. Gaudiano and I. W. Miller, "The evidence-based practice of psychotherapy: facing the challenges that lie ahead," Clinical Psychology Review, vol. 33, no. 7, pp. 813-824, 2013.

[39] J. W. Park, G. T. Clark, Y. K. Kim, and J. W. Chung, "Analysis of thermal pain sensitivity and psychological profiles in different subgroups of TMD patients," International Journal of Oral and Maxillofacial Surgery, vol. 39, no. 10, pp. 968-974, 2010.

[40] S. Kindler, S. Samietz, M. Houshmand et al., "Depressive and anxiety symptoms as risk factors for temporomandibular joint pain: a prospective cohort study in the general population," Journal of Pain, vol. 13, no. 12, pp. 1188-1197, 2012.

[41] S. J. Scrivani, D. A. Keith, and L. B. Kaban, "Temporomandibular disorders," The New England Journal of Medicine, vol. 359, no. 25, pp. 2693-2705, 2008.

[42] A. Kumar and M. T. Brennan, "Differential diagnosis of orofacial pain and temporomandibular disorder," Dental Clinics of North America, vol. 57, no. 3, pp. 419-428, 2013.

[43] S. S. De Rossi, I. Stern, and T. P. Sollecito, "Disorders of the masticatory muscles," Dental Clinics of North America, vol. 57, no. 3, pp. 449-464, 2013.

[44] M. Wallden, "The trapezius_clinical \& conditioning controversies," Journal of Bodywork and Movement Therapies, vol. 18, no. 2, pp. 282-291, 2014.

[45] D. J. Mayer, "Biological mechanisms of acupuncture," Progress in Brain Research, vol. 122, pp. 457-477, 2000.

[46] C. Carlsson, "Acupuncture mechanisms for clinically relevant long-term effects-reconsideration and a hypothesis," Acupuncture in Medicine, vol. 20, no. 2-3, pp. 82-99, 2002. 


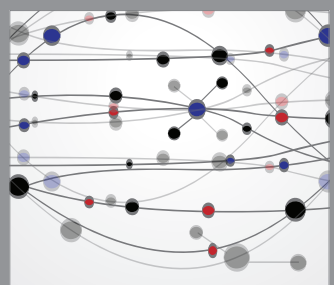

The Scientific World Journal
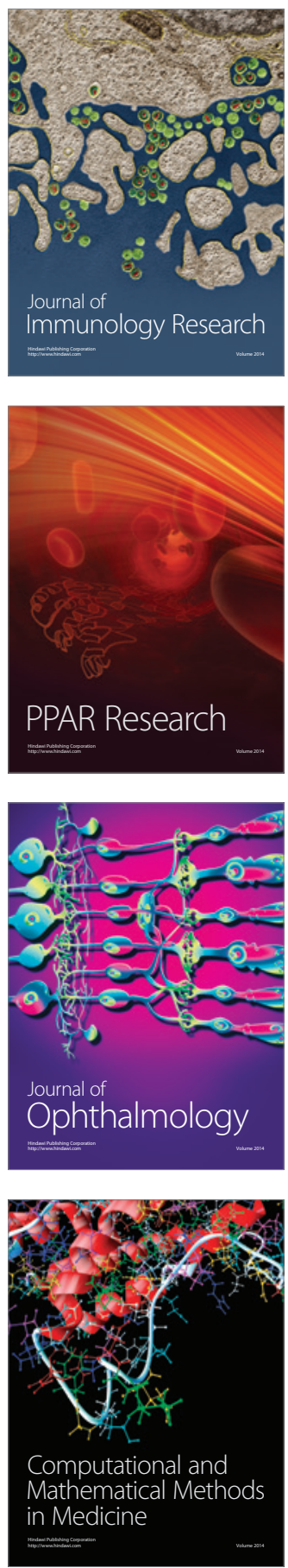

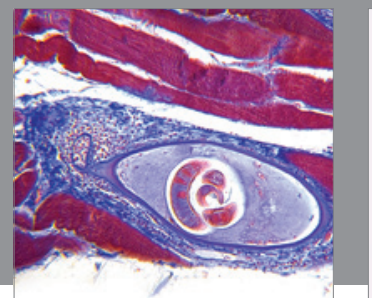

Gastroenterology

Research and Practice
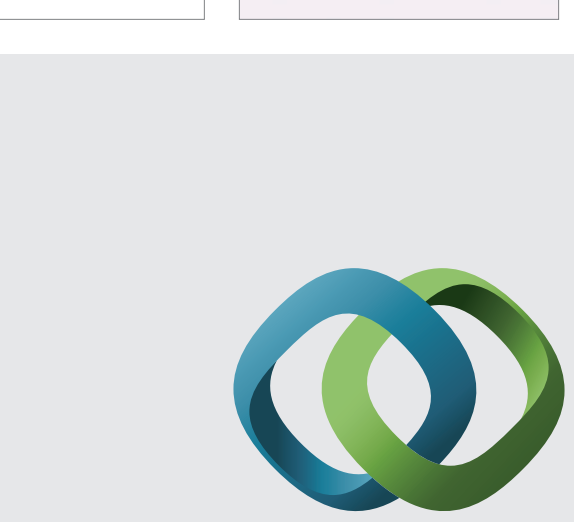

\section{Hindawi}

Submit your manuscripts at

http://www.hindawi.com
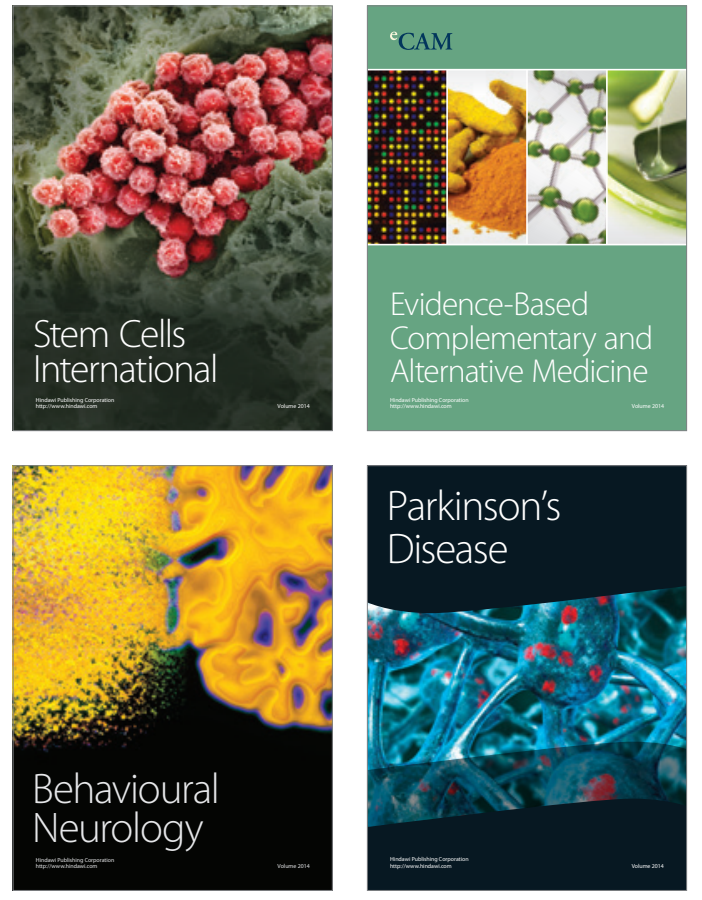
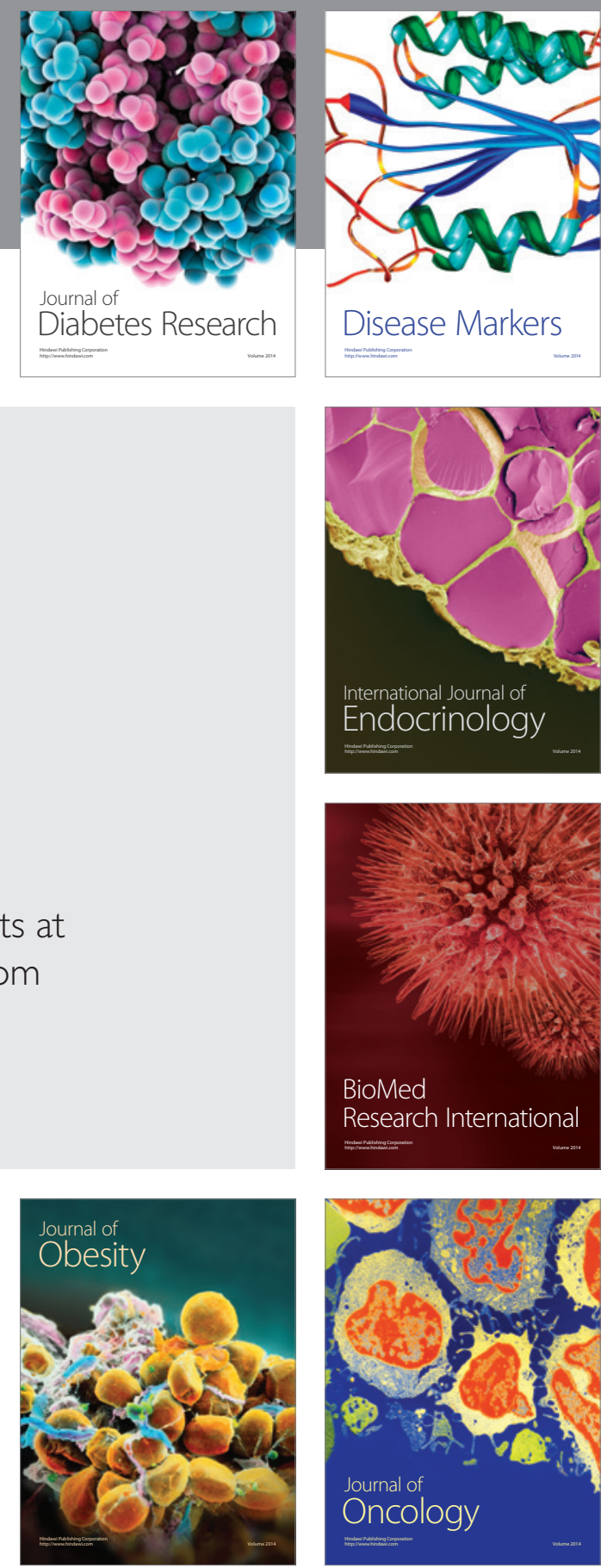

Disease Markers
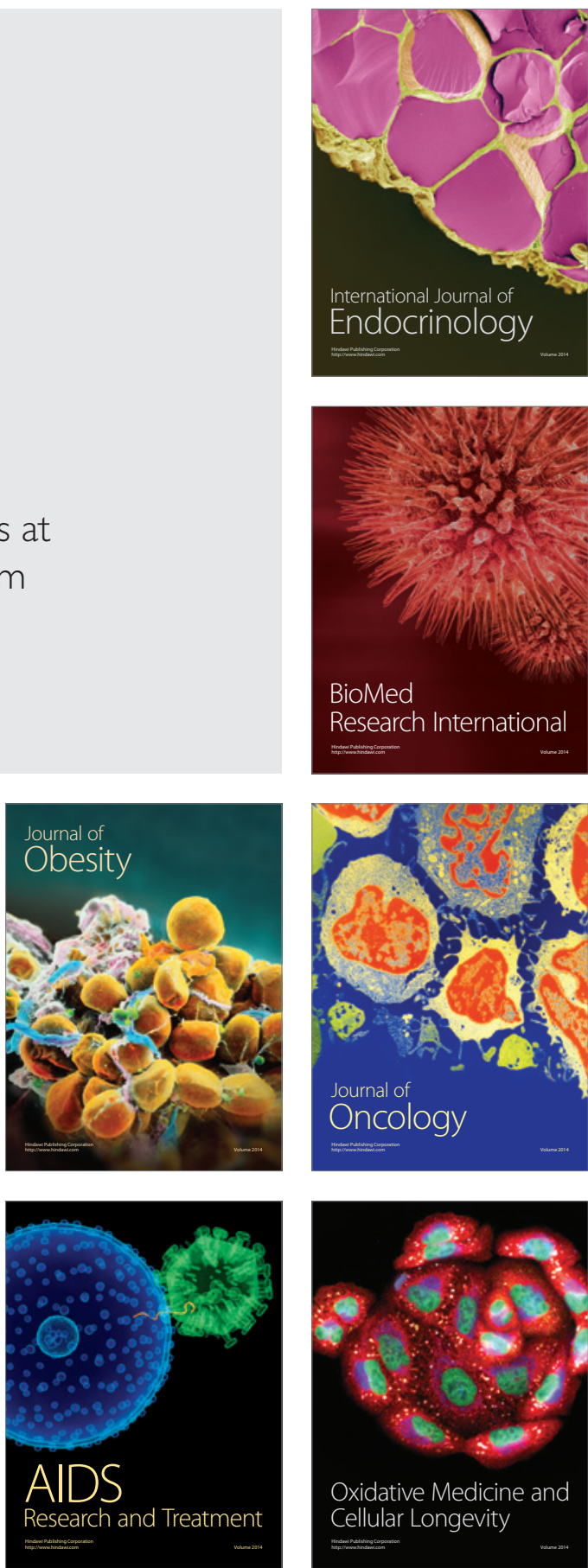